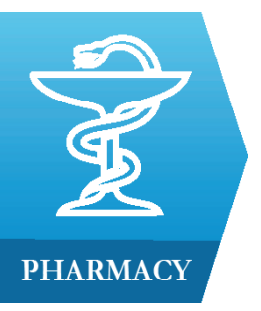

1) Department of Pharmacology, Physiology and Physiopathology, Faculty of Pharmacy, Iuliu Haţieganu University of Medicine and Pharmacy, Cluj-Napoca, Romania

2) Drug Information Research Center, Iuliu Hatieganu University of Medicine and Pharmacy, Cluj-Napoca, Romania

3) Department of Medical Informatics and Biostatistics, Iuliu Hatieganu University of Medicine and Pharmacy, Cluj-Napoca, Romania

\title{
Survery of healthcare professionals to assess the awareness, knowledge and self-reported behavior regarding recent fluoroquinolones safety issues
}

\author{
Madalina Huruba ${ }^{1}$, Andreea Farcas ${ }^{2}$, Daniel Corneliu Leucuta ${ }^{3}$, \\ Mariana $\operatorname{Sipos}^{1}$, Cristina Mogosan ${ }^{1,2}$
}

\begin{abstract}
Background and aims. The impact of fluoroquinolone (FQ)-induced long-lasting, disabling, and potentially irreversible serious adverse drug reactions (ADRs) on the overall benefit-risk balance and the need for adequate risk minimization measures has been recently assessed. The present study aims to evaluate physicians and pharmacists' awareness and knowledge of the recent safety issues communicated through a direct healthcare professional communication (DHPC), regarding FQs, at a national level, in Romania, as well as healthcare professionals (HPs) self-reported behavior regarding the management of the risk.

Methods. Cross-sectional, online survey study, conducted in Romania.

Results. A total of 127 participants responded to the survey. Six (4.7\%) were physicians and 121 (95.3\%) were pharmacists. The predominant age was 31-40 years $(\mathrm{N}=52,40.9 \%)$, and most respondents were females $(\mathrm{N}=117,92.1 \%)$. A majority of $101(79.5 \%)$ were reportedly aware of the existence of the new safety issues associated with FQs, and slightly less were aware of the DHPC $(\mathrm{N}=86,67.7 \%)$ issued in 2019. In terms of knowledge, slightly more than half of the respondents had correctly selected the responses regarding key safety messages on most important ADRs and restrictions / cautions for use. The impact of the communication on HPs self-reported behavior was high or very high in almost half of the participants $(\mathrm{N}=63,49.6 \%)$.

Conclusions. A high percentage of participants were aware of the FQ-associated safety concerns. Knowledge was relatively good for the key safety concerns among HPs. A notable impact on behavior was observed, mostly in terms of counselling of the patient and disseminating the information to colleagues.
\end{abstract}

Keywords: fluoroquinolones, health personnel, pharmacists, self report, Romania

\section{Background and aims}

Fluoroquinolones (FQs) are a class of broad-spectrum, systemic antibacterial agents widely used as therapy for respiratory and urinary tract infections [1]. Generally welltolerated and relatively safe, specific adverse effects are, however, common with all agents in this antibiotic class. Gastrointestinal and central nervous system (CNS) effects are the most frequent adverse drug reactions (ADRs), occurring in $2-20 \%$ of patients treated with (fluoro)quinolones [2]. Recently, FQinduced ADRs affecting body systems like musculoskeletal, senses (vision, hearing, etc.), neuropsychiatric, skin, peripheral nervous system, and cardiovascular system have raised medicines regulatory agencies' attention [3].

Upon authorization, the safety profile of a drug is incomplete on 
account of pre-marketing clinical trials inherent and known shortcomings [4], and thus an effective risk characterization and communication plan become essential in the prevention and minimization of harm in the post-authorization phase [5]. In light of this, pharmacovigilance (PV) systems allow to continuously monitor drug safety and to minimize the risks. The ultimate goal of these regulatory systems is to detect changes in the benefit-risk balance of a medicine from routine clinical use [6].

In 2016, the US Food and Drug Administration (FDA) issued a drug safety communication restricting FQ use for certain uncomplicated infections and warning about FQ-induced disabling side effects. Side effects involving the tendons, muscles, joints, nerves, and CNS were at the basis of safety communication [7]. Similarly, in 2017, the European Medicines Agency (EMA) initiated a safety assessment of FQs (i.e., referral under Article 31 of Directive 2001/83/EC), evaluating the impact of FQ-induced longlasting, disabling, and potentially irreversible serious ADRs on the overall benefit-risk balance and the need for adequate risk minimization measures (RMMs). Consequently, suspension of the marketing authorizations of nalidixic acid, pipemidic acid, cinoxacin, and flumequine was concluded, as well as restrictions of use for the remaining targeted FQs (e.g., pefloxacin, lomefloxacin, ciprofloxacin, levofloxacin, ofloxacin, moxifloxacin, norfloxacin, prulifloxacin, rufloxacin) [3].

Imposed RMMs consisted of routine measures, such as the update of the product information (PI), mainly aiming to reflect and minimize the risk of fluoro(quinolone)-induced ADRs. A direct healthcare professional communication (DHPC) was proposed to be sent to the health care professionals (HPs), thus increasing the awareness of the risk as well as on the associated changes to the PI. In European countries, the DHPC is one of the most commonly used safety communication tools [8]. A DHPC is a communication intervention informing individual HPs about the need for certain actions to be taken or certain practices to be adopted, in relation to a medicinal product, and it is considered an additional risk minimization measure (aRMM) [9].According to recent findings, around $10-14 \%$ of medicinal products require a DHPC informing HPs regarding newly identified risks within the first three years after market approval [5]. The National Agency for Medicines and Medical Devices of Romania (NAMMDR) published on their website the DHPC regarding FQ-associated long-lasting, disabling, potentially irreversible serious ADRs and restrictions and precautions for FQs use on March 2019 [10].

In Europe, DHPCs can be issued by National Competent Authorities (NCAs) or Marketing Authorization Holders (MAHs) [8], being distributed to individual HPs and/or made available on the NCA's website. In Romania, the NCA (i.e., NAMMDR) publishes the safety communications on their website and, at least sometimes, disseminates DHPCs via electronic means in addition to distribution by companies [11]. Professional organizations usually take this information and disseminate it to their members via e-mail, social media, or their webpages. Medical media too are involved in disseminating relevant safety information through their communication channels.

Since 2012, the European PV legislation requires routine monitoring of the impact of these regulatory safety communications to evaluate the effectiveness of the proposed RMMs [8]. The evaluation of RMMs is relevant in deciding on the efficacy of the risk management, and in case the efficacy is not demonstrated, the evaluation helps to identify correction measures. To this extent, two categories of indicators are considered: process and outcome indicators. Process indicators provide insight into the implementation of aRMMs as planned, the execution, and the impact of the measures on the intended risk management (e.g., receipt, awareness, knowledge, utilization, behavior) [9]. Given that the effectiveness of risk communication is strongly correlated with the trust in the source of the information, evaluation of how different sources are perceived by HPs is of great importance as well [5].

The present study aims to evaluate physicians and pharmacists (i.e., HPs) awareness and knowledge of the recent safety issues communicated for FQs, at a national level, in Romania, as well as HPs self-reported behavior regarding the management of the risk.

\section{Methods}

This is a cross-sectional, survey-based study conducted in Romania. The study protocol and questionnaire were approved by the Ethics Committee of the University of Medicine and Pharmacy, Cluj-Napoca, no $275 / 30.07 .2020$. The survey was distributed online, via social media, particularly via medical and pharmacists groups. These groups were designed as 'closed', meaning that an admin approval of the account was required before being allowed into the group community. This procedure allows for some control regarding the exclusion of fake accounts, or even accounts belonging to non-HPs. The survey was anonymous and targeted physicians/medical doctors (MDs) (regardless of specialty) and pharmacists, who gave their consent in filling in the survey. Specific confirmation of the healthcare professional status was required, with a negative response automatically leading the user to the end of the questionnaire. The survey was open for one month, with the first dissemination on the $4^{\text {th }}$ of October and the last reminder posted on the $2^{\text {nd }}$ of November. Two more reminders were posted during the month of October.

\section{Questionnaire Development}

No validated questionnaires for aRMM assessment could be retrieved after an explorative literature search. Therefore, a questionnaire was developed using openended and closed questions. These were specifically designed to evaluate process indicators such as awareness, 
knowledge and self-reported behavior of HPs. The attitude of HPs towards safety concerns in terms of keeping up with the latest information and the frequency of checking the NAMMDR webpage for DHPCs was evaluated as well.

Questions evaluating knowledge were represented by statements with three possible response alternatives (i.e., true, false, or I don't know). With regards to the question on active substances withdrawn, for consistency in the analysis, a true response was considered a marked checkbox for the respective active substance, and false when the checkbox was not marked; I don't know was a possible response alternative for this question.

Behavior was evaluated on a scale of 1 to 5 , where 1 represented a very low impact and 5 a very high impact on HPs behavior, as well as in terms of specific changes (i.e., change in prescription behavior, patient counselling and monitoring, etc.).

Descriptive statistical analysis was performed, using counts and percentages, and the results were stratified dependent on the participants' characteristics, provided that no less than 10 participants represented a minority group. Fisher exact test was used to compare answers for those who fully read and those who didn't read the communication in a certain category. Two tailed p-values were computed, and a 0.05 level of significance was used. All statistical analysis were carried out with the $\mathrm{R}$ environment for statistical computing and graphics (R Foundation for Statistical Computing, Vienna, Austria), version 4.0.3.

\section{Results}

A total of 127 participants responded to the survey. All surveys were valid (i.e., had all mandatory questions addressed, and evaluable responses) and were therefore included in the analysis. Among the participants, 6 (4.7\%) were physicians, and 121 (95.3\%) were pharmacists. The predominant age was $31-40$ years $(\mathrm{N}=52,40.9 \%)$, and most respondents were females $(\mathrm{N}=117,92.1 \%)$. The majority of respondents had a healthcare experience between 2-20 years $(\mathrm{N}=92,72.4 \%)$ and were based in the urban area $(\mathrm{N}=120,94.5 \%)$ (Table I).

All 127 respondents considered information related to drug safety to be of importance. However, 40 (31.5\%) of them found keeping up to date with the latest drug safety information to be time-consuming.

Ninety-four (74.0\%) of respondents reported to have seen a DHPC at least once. Among the 78 respondents who reportedly routinely check (at various time intervals) the NAMMDR page for DHPCs, $63(80.8 \%)$ stated that they always took into account the DHPC recommendations, with fewer stating they only sometimes take the recommendations into account $(\mathrm{N}=14,17.9 \%)$.

With regards to sources of safety information that were voluntarily researched, most participants marked more than one source, with the majority $(\mathrm{N}=89$ participants, $70.1 \%$ ) choosing the NAMMDR website, followed by the EMA website ( $\mathrm{N}=66$ participants, $52.0 \%$ ), peer reviewed publications $(\mathrm{N}=56,44.1 \%)$, phone applications $(\mathrm{N}=49$, $38.6 \%)$, social media $(\mathrm{N}=39,30.7 \%)$ and medical media $(\mathrm{N}=38,29.9 \%)$.

Table I. Demographic data of respondents.

$\begin{array}{lccc}\text { Gender } & \text { Female } & \text { Male } & \text { Total } \\ \text { Profession } & & & \\ \text { Physician } & 5 & 1 & 6 \\ \text { Pharmacist } & 112 & 9 & 121 \\ \text { Age (years) } & & & \\ 22-30 & 40 & 5 & 45 \\ 31-40 & 50 & 2 & 52 \\ 41-60 & 26 & 3 & 29 \\ \geq 60 & 1 & 0 & 1 \\ \text { Healthcare experience (years) } & & \\ <2 & 11 & 2 & 13 \\ 2-5 & 30 & 4 & 34 \\ 6-10 & 28 & 1 & 29 \\ 11-20 & 28 & 1 & 29 \\ >20 & 20 & 2 & 22 \\ \text { Area } & & & \\ \text { Urban } & 110 & 10 & 120 \\ \text { Rural } & 7 & 0 & 7\end{array}$

The preferred way of communication of future safety issues was also assessed. A high majority of participants $(\mathrm{N}=117,92.1 \%)$ opted for electronic communication (via e-mail).

\section{Awareness}

From the total number of participants, a majority of 101 respondents $(79.5 \%)$ were reportedly aware of the existence of the new safety issues associated with FQs, while a slightly lower proportion were aware of the DHPC $(\mathrm{N}=86$, $67.7 \%$ ) issued in 2019.

Sixty-three $(49.6 \%)$ of participants reported having received the communication regardless of means or source. The highest majority of respondents $(\mathrm{N}=43,33.9 \%)$ were aware of the communication from the NAMMDR. A relatively high proportion of respondents were also aware of the communication from colleagues $(\mathrm{N}=34,26.8 \%)$, followed by information received from the workplace $(\mathrm{N}=28,22.0 \%)$, from the National College of Pharmacists (i.e., Colegiul Farmaciștilor din România) ( $\mathrm{N}=21,16.5 \%$ ), awareness from the EMA $(\mathrm{N}=16,12.6 \%)$ and the MAH $(\mathrm{N}=15,11.8 \%)$.

Overall, $54(42.5 \%)$ participants fully read the communication, 43 (33.9\%) only partially read it, and 30 $(23.6 \%)$ did not read it at all.

From the total 97 of participants who read the communication (in full or partially), all found the information useful to some extent $(\mathrm{N}=67,69.1 \%$ very useful, and $\mathrm{N}=30$, $30.9 \%$ somewhat useful). 


\section{Knowledge}

Knowledge regarding the aspects depicted in the communication was tested via the survey. Most respondents had correctly selected the responses, with more than $80 \%$ correct responses for 9 statements out of 32 (28.1\%), out of which five were regarding FQs induced ADRs and restrictions/ cautions for use (Table II). However, perhaps due to the fact that some of these were not previously authorized in Romania, some issues were noted with regards to the withdrawn medicinal products, with the majority of participants failing to correctly identify pipemidic acid $(\mathrm{N}=90)$, cinoxacin $(\mathrm{N}=99)$, flumequine $(\mathrm{N}=88)$, and nalidixic acid $(\mathrm{N}=74)$ as withdrawn medicinal products. A total of 60 respondents did not know which (fluoro)quinolone was withdrawn.

Table II. Responses to questions targeting the level of knowledge of FQ safety issues.

\begin{tabular}{|c|c|c|c|c|}
\hline FQ-induced ADRs*: & True & False & Don't know & Correct responses $(\%)$ \\
\hline Affect muscles, tendons, and joints & 113 & 6 & 8 & 89.0 \\
\hline Affect the peripheral nervous system & 65 & 24 & 38 & 51.2 \\
\hline Affect the sensorial organs (impairment of vision, hearing, smell, and taste) & 66 & 28 & 33 & 52.0 \\
\hline Affect the skin & 53 & 45 & 29 & 41.7 \\
\hline Affect the CNS & 70 & 19 & 38 & 55.1 \\
\hline Affect the gastrointestinal system & 64 & 31 & 32 & 24.4 \\
\hline Affect the cardiovascular system & 79 & 24 & 24 & 62.2 \\
\hline Correct responses (\%) - mean & & & & 53.7 \\
\hline ADRs characteristics* & True & False & Don't know & Correct responses $(\%)$ \\
\hline Disabling & 75 & 12 & 40 & 59.1 \\
\hline Potentially irreversible & 92 & 15 & 20 & 72.4 \\
\hline Long-lasting (months or even years) & 89 & 11 & 27 & 70.1 \\
\hline Common for the entire quinolone class & 89 & 18 & 20 & 70.1 \\
\hline Can occur 48 hours after FQ treatment initiation & 77 & 12 & 38 & 60.6 \\
\hline Can occur several months after FQ treatment discontinuation & 60 & 24 & 67 & 47.2 \\
\hline Correct responses (\%) - mean & & & & 63.3 \\
\hline Withdrawn (fluoro)quinolones* & True & False** & Don't know & Correct responses (\%) \\
\hline Flumequin & 39 & 88 & \multirow{9}{*}{60} & 30.7 \\
\hline Norfloxacin & 4 & 123 & & 96.9 \\
\hline Ofloxacin & 3 & 124 & & 97.6 \\
\hline Cinoxacin & 28 & 99 & & 22.0 \\
\hline Moxifloxacin & 9 & 118 & & 92.9 \\
\hline Pefloxacin & 14 & 113 & & 89.0 \\
\hline Nalidixic acid & 53 & 74 & & 41.7 \\
\hline Pipemidic acid & 37 & 90 & & 29.1 \\
\hline Correct responses (\%) - mean & & & & 62.5 \\
\hline Statements on FQ use* & True & False & Don't know & Correct responses $(\%)$ \\
\hline $\begin{array}{l}\text { Recommended NOT to be used to treat mild to moderate infections } \\
\text { unless other antibiotics that are commonly recommended for these } \\
\text { infections are considered inappropriate }\end{array}$ & 122 & 1 & 4 & 96.1 \\
\hline $\begin{array}{l}\text { Can be used for patients who have previously had serious ADRs with a } \\
\text { (fluoro)quinolone antibiotic }\end{array}$ & 6 & 114 & 7 & 89.8 \\
\hline Can be used to treat pharyngeal infections & 33 & 75 & 19 & 59.1 \\
\hline $\begin{array}{l}\text { Can be used to treat non-bacterial infections, e.g. non-bacterial (chronic) } \\
\text { prostatitis }\end{array}$ & 27 & 77 & 23 & 60.6 \\
\hline Can be used for preventing travelers' diarrhea & 31 & 84 & 12 & 66.1 \\
\hline Can be used for preventing recurrent lower urinary tract infections & 74 & 45 & 8 & 35.4 \\
\hline Correct responses $(\%)$ - mean per $Q$ & & & & 67.8 \\
\hline FQ use prescribed special caution for\%: & True & False & Don't know & Correct responses $(\%)$ \\
\hline The elderly & 113 & 7 & 7 & 89.0 \\
\hline Patients with renal impairment & 104 & 15 & 8 & 81.9 \\
\hline Patients with solid organ transplants & 92 & 12 & 23 & 72.4 \\
\hline Immunocompromised patients with infections & 80 & 26 & 21 & 20.5 \\
\hline Patients concurrently treated with systemic corticosteroids & 97 & 14 & 16 & 76.4 \\
\hline Correct responses (\%) - mean & & & & 68.0 \\
\hline Correct responses (\%) - mean overall & & & & 63.1 \\
\hline
\end{tabular}

Q: Question; *Questions with multiple answers; **False represents the cases where the active substance was not selected as withdrawn from the market, whereas True represents the cases where the active substance was selected. 
Table III. Differences in responses of participants who fully read the DHPC vs. those who only partially read it for the two top highest scored questions.

\begin{tabular}{|c|c|c|c|c|c|}
\hline Statements on FQ use & $\begin{array}{l}\text { Reading } \\
\text { status }\end{array}$ & True & False & Don't know & P-value \\
\hline $\begin{array}{l}\text { Recommended NOT to be used to treat mild to moderate } \\
\text { infections unless other antibiotics that are commonly } \\
\text { recommended for these infections are considered inappropriate }\end{array}$ & $\begin{array}{l}F R \\
P R\end{array}$ & $\begin{array}{c}53(98.1) \\
43(100.0)\end{array}$ & $\begin{array}{l}1(1.9) \\
0(0.0)\end{array}$ & $\begin{array}{l}0(0.0) \\
0(0.0)\end{array}$ & 1 \\
\hline $\begin{array}{l}\text { Can be used for patients who have previously had serious ADRs } \\
\text { with a (fluoro)quinolone antibiotic }\end{array}$ & $\begin{array}{l}F R \\
P R\end{array}$ & $\begin{array}{l}3(5.6) \\
2(4.7)\end{array}$ & $\begin{array}{l}50(92.6) \\
41(95.3)\end{array}$ & $\begin{array}{l}1(1.9) \\
0(0,0)\end{array}$ & 1 \\
\hline Can be used to treat pharyngeal infections & $\begin{array}{l}F R \\
P R\end{array}$ & $\begin{array}{l}10(18.5) \\
13(30.2)\end{array}$ & $\begin{array}{l}37(68.5) \\
24(55.8)\end{array}$ & $\begin{array}{l}7(13) \\
6(14)\end{array}$ & 0.36 \\
\hline $\begin{array}{l}\text { Can be used to treat non-bacterial infections, e.g., non-bacterial } \\
\text { (chronic) prostatitis }\end{array}$ & $\begin{array}{l}F R \\
P R\end{array}$ & $\begin{array}{c}7(13.0) \\
12(27.9)\end{array}$ & $\begin{array}{l}38(70.4) \\
21(48.8)\end{array}$ & $\begin{array}{c}9(16.7) \\
10(23.3)\end{array}$ & 0.095 \\
\hline Can be used for preventing travelers' diarrhea & $\begin{array}{l}F R \\
P R\end{array}$ & $\begin{array}{l}11(20.5) \\
13(30.2)\end{array}$ & $\begin{array}{l}42(77.8) \\
24(55.8)\end{array}$ & $\begin{array}{l}1(1.9) \\
6(14.0)\end{array}$ & 0.025 \\
\hline $\begin{array}{l}\text { Can be used for preventing recurrent lower urinary tract } \\
\text { infections }\end{array}$ & $\begin{array}{l}F R \\
P R\end{array}$ & $\begin{array}{l}25(46.3) \\
29(67.4)\end{array}$ & $\begin{array}{l}26(48.1) \\
11(25.6)\end{array}$ & $\begin{array}{l}3(5.6) \\
3(7.0)\end{array}$ & 0.070 \\
\hline FQ use prescribed special caution for & & True & False & Don't know & \\
\hline The elderly & $\begin{array}{l}F R \\
P R\end{array}$ & $\begin{array}{l}50(96.2) \\
37(86.0)\end{array}$ & $\begin{array}{c}1(1.9) \\
5(11.6)\end{array}$ & $\begin{array}{l}3(5.6) \\
1(2.3)\end{array}$ & 0.110 \\
\hline Patients with renal impairment & $\begin{array}{l}F R \\
P R\end{array}$ & $\begin{array}{l}47(87.0) \\
36(83.7)\end{array}$ & $\begin{array}{l}5(9.3) \\
6(14.0)\end{array}$ & $\begin{array}{l}2(3.7) \\
1(2.3)\end{array}$ & 0.805 \\
\hline Patients with solid organ transplants & $\begin{array}{l}F R \\
P R\end{array}$ & $\begin{array}{l}40(74.1) \\
33(76.1)\end{array}$ & $\begin{array}{c}5(9.3) \\
5(11.6)\end{array}$ & $\begin{array}{l}9(16.7) \\
5(11.6)\end{array}$ & 0.787 \\
\hline Immunocompromised patients with infections & $\begin{array}{l}F R \\
P R\end{array}$ & $\begin{array}{l}33(61.1) \\
26(60.5)\end{array}$ & $\begin{array}{l}13(24.1) \\
11(25.6)\end{array}$ & $\begin{array}{l}8(14.8) \\
6(14.0)\end{array}$ & 1 \\
\hline Patients concurrently treated with systemic corticosteroids & $\begin{array}{l}F R \\
P R\end{array}$ & $\begin{array}{l}45(83.3) \\
30(69.8)\end{array}$ & $\begin{array}{c}5(9.3) \\
7(16.3)\end{array}$ & $\begin{array}{c}4(7.4) \\
6(14.0)\end{array}$ & 0.328 \\
\hline
\end{tabular}

DHPC: Direct healthcare professionals communication; Data are presented as counts (\%); FR: Fully read DHP represents the number of participants who fully read the communication in a certain category; PR: Partially read DHP represents the number of participants who partially read the communication in a certain category. The bolded text represents the number of correct responses.

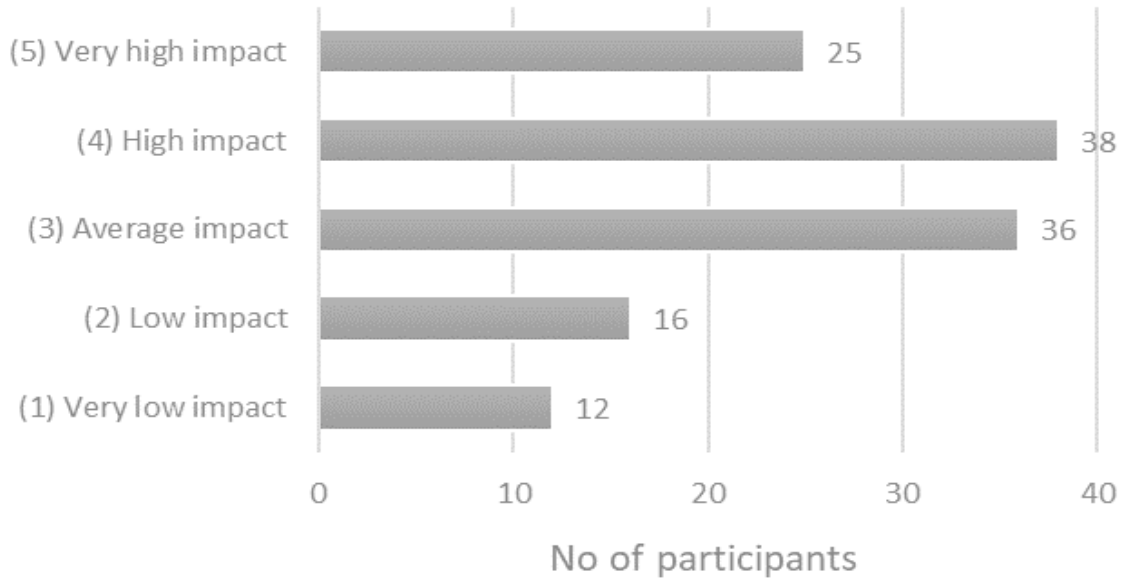

Figure 1. Behavioral impact of the DHP on a 1 to 5 scale. 
Differences in responses of participants who fully read the DHPC as opposed to those who only partially read it for the two questions on FQs restrictions and cautions for use imposed for risk minimization are depicted in table III. Generally, more participants who fully read the communication selected the correct responses. However, the difference was statistically significant for one question, and relatively close to the level of significance for other 3 questions.

\section{Behavior}

In terms of the impact of the communication on HPs' behavior, most respondents estimated that the impact was high (i.e., level 4 on the scale, $\mathrm{N}=38,29.9 \%$ ) and very high (i.e., level 5 on the scale, $\mathrm{N}=25,19.7 \%$ ), while 12 $(9.4 \%)$ stated that very low impact was generated by the communication (Figure 1).

Overall, with regards to the specific change of behavior, the majority of participants stated that they counseled the patient concerning the potential ADRs $(\mathrm{N}=80,63 \%)$; Seventy-eight $(61.4 \%)$ of them communicated the information to fellow colleagues, and $54(42.5 \%)$ monitored their patients even closer. Of note is the fact that more than one change in behavior could have been chosen.

\section{Discussion}

To our knowledge, although small in size, this is the first study to evaluate the effectiveness of the DHPC issued on account of long-lasting, disabling, and potentially irreversible FQ-induced serious ADRs in Romania. Surveys are a well-established standard to measure process indicators [11] such as awareness of RMMs, as well as knowledge and self-reported behavior. Similar study design was reported by a qualitative review of 19 RMMs effectiveness studies, 11 of which were cross-sectional surveys and eight were conducted online. Generally, RMMs were evaluated using process indicators [12]. The timeframe for conducting such a survey is recommended to be 12 to 18 months after the implementation of the aRMM [9], (i.e., March 2019 in Romania). We initiated the dissemination of the surveys in October 2020, 18 months after NAMMDR issued the communication.

To this extent, process indicators such as awareness, knowledge, and self-reported behavior of HPs (i.e., physicians and pharmacists) were evaluated at a national level, in Romania. Despite having published the survey on social media on both medical and pharmacists' groups with an equal frequency, a very low rate of responses among physicians was observed, with only six $(4.7 \%)$ responses. Overall, the majority of participants were women $(92.1 \%)$, and the predominant area of participants was urban (94.5\%).

The predominant age group of participants was 31$40(40.9 \%)$, closely followed by $22-30(35.4 \%)$, suggesting perhaps that younger HPs are more open to filling in questionnaires and perhaps more familiar with online means and social media. In terms of healthcare experience, the participants tended to be well distributed among experience years groups.

Despite the fact that $100 \%$ of participants found drug-risk information to be of importance, one third (31.5\%) admitted that keeping up to date was time-consuming. Similar results were observed during a survey conducted in the Netherlands, showing that general practitioners also indicated that keeping up to date regarding new drug safety issues took too much time [5].

Regarding awareness, similar high proportions of participants were aware of the safety concerns or the communication of the same via the DHPC, with $69.8 \%$ being aware of either one or both. Naturally, awareness of a safety issue is the first step of the process; therefore, before HPs can act on it, the physicians and pharmacists first need to become aware of it [8]. Similar studies have generally shown lower levels of awareness with regards to drug safety issues $[5,8,13]$. Even if high in our analysis, awareness is not a definite indicator of knowledge since it might be a result of simply hearing or reading about the DHPC, but that does not automatically imply reading the content and accumulating knowledge. Despite the high awareness of the communication, only around half of the participants $(49.6 \%)$ reported having actively received the DHPC. Educational materials represent another means of communication of safety measures in the form of aRMMs, with the scope of minimizing the risk [9], and studies have proved that if received, educational material is highly likely to be read and used, varying on the type of measure [14]. Therefore, active receipt of a DHPC can perhaps ultimately have a positive impact on reading the content and therefore accumulating information on key safety risks and minimization measures. The alternative that HPs might have picked up information on FQs safety issues and RMMs via other sources than the DHPC in our survey could suggest poor effectiveness of the DHPC, as demonstrated in other studies [15].

Regarding information sources voluntarily researched by the HPs, sources like the NAMMDR's website and EMA's website scored among the highest ones. Of note, generally, knowledge of safety concerns may come from several sources such as company representatives, medical conferences as well as protocols in hospital departments, which may be more likely to be used by HPs [14]. To this extent, in our study, sources like peer-reviewed publications, phone applications, and even medical or social media, tended to also have quite a high appeal (ranging from 30 to $44 \%$ ) among participants. In an era where social media gains more and more ground, drug safety issues (social or lay) media attention and communication might have a notable impact on the level of awareness among HPs. However, a study evaluating the coverage of drug safety issues by the lay media found that 
some drug safety issues received extensive media attention instead of others, indicating that coverage of drug safety issues is not always as balanced as one would prefer [8].

Regarding the means of communication, similarly to a previous survey-based study where some HPs suggested using online means for disseminating the DHPC, on account of the advantage of issuing the information immediately to a large population [14], in our study, the majority of participants opted for online communication as well.

Knowledge was evaluated in all study participants, regardless of their mentioning of having been aware of the recent safety issues or the communication (questions on knowledge were mandatory for all respondents). Notably, $70 \%$ of respondents were aware of the safety issues, and/ or the communication, while overall, for all knowledge questions, the mean proportion of correct responses in terms of knowledge was around $60 \%$, thus suggesting a rather low impact of awareness on knowledge and might even be an indication of poor DHPC effectiveness. Several other studies assessing knowledge on different RMMs considered that adequate knowledge was achieved if a predefined threshold of $80 \%$ of correct responses was reached $[8,16]$. In our study this threshold was reached for 9 statements out of 32. Five of these statements were with regard of (i) the ADRs affecting the musculoskeletal system, as well as the restrictions of use in (ii) mild to moderate infections and in (iii) patients who have previously had serious ADRs with FQs, and for cautions for use in (iv) the elderly patients and in (v) patients with renal impairment. These being among the most important key safety messages of the DHPC, a high proportion of correct responses for these statements could perhaps suggest a positive impact on the HPs knowledge, from this point of view. The rest of the 4 correct responses reaching the threshold were for the (fluoro) quinolones withdrawn.

A second analysis was performed for the two questions on FQs restrictions and cautions for use imposed for risk minimization, comparing the knowledge of participants who fully read the DHPC versus those who only partially read it. As expected, participants who fully read the DHPC tended to generally score higher, thus suggesting a reasonably effective communication of key safety risks within this group. Worth mentioning is the fact that only for few statements the $80 \%$ threshold of correct responses was reached, regardless of the communication being partially or fully read.

The behavior of HPs, and all involved stakeholders has a great impact on risk management [17]. Going back to Rasmussen's skills, rules, knowledge theory, a certain level of attention must be given to the three levels of competence in order to prevent erroneous behavior. Extrapolating the theory to $\mathrm{PV}$, one can attest that by gathering postauthorization information about the medicinal product, we are accumulating new knowledge in terms of potential new risks associated with medicinal products. Communication of the risk becomes an important pillar in the process of PV, thus sharing knowledge with HPs is of utmost importance [18]. The DHPCs are a common form of risk communication in public health, with an increase in the number of DHPCs issued in the last decades [19]. Naturally, we expect knowledge to determine an expected change in behavior. The effectiveness of DHPCs on reaching intended clinical behavior change has been previously questioned [19], and a poor impact of communication strategies has been reported [14]. Consequently, it becomes clear that besides communication of the risk via the DHPC, some other measures should be employed, especially as we are aiming to change an aspect enclosed in the highest level of competence - skills, ultimately aiming to optimize the benefit-risk ratio of drugs in terms of safe use of drugs and patient safety. Overall, the impact of the communication on HPs self-reported behavior was high (i.e., 49.6\% reported a level of impact above 3 (high, and very high), with considerably less below 3 (low, very low, 22\%). Behavior changes were mostly reflected in the counseling of the patients, most likely due to the fact that the large majority of respondents were pharmacists and thus having patient counselling as a primary responsibility. A high proportion of participants communicated the information to fellow colleagues and monitored their patients even closer. Despite encouraging results regarding self-reported behavior, in order to evaluate the effectiveness of aRMM in terms of change in clinical actions, drug utilization studies (DUS) are recommended by the Good Pharmacovigilance Practices (GVP). The analysis of prescription records may allow the evaluation of prescribing behavior and patient selection and monitoring [9].

\section{Limitations}

A notable limitation of the present study was the very low response rate among physicians, especially as they were the primary target of the communication. Thus, we could not assess a potential change in prescription behavior among physicians. A further DUS on FQ could allow for this evaluation. Despite the survey being disseminated among pharmacists as well as physicians' social groups with the same frequency of reposting, no improvement in the response rate among physicians was noted. As such, no comparative evaluation between the two HPs categories was possible. Overall, the study was small in size. However, similar low numbers of participants were reported by a review of RMMs effectiveness studies, mentioning a range of participants per country from 2 to 212 [12]. Some impact on the predominant age group of the respondents [i.e., 31-40 years old (40.9\%)] could have been implied by the dissemination of the survey via social media.

To be noted that we did not target prescribing physicians exclusively, also on account of the fact that 
to the best of our knowledge, no specific distribution of DHPCs on FQs among prescribers by NAMMDR nor MAH was in place. We aimed to get a perspective on HPs in general, and we included pharmacists on account of their crucial role in patient counselling, especially in the case of highly prescribed medication, such as FQs. Due to the low response rate of the survey, the results of the present analysis cannot be generalized at national level and among all HPs, but merely offers an indicative of tendencies with regards to awareness, knowledge and self-reported behavior among our cohort of HPs, concerning FQs safety issues. Furthermore, as with all surveys measuring knowledge, most participants respond to the questions by recalling specific events rather than all events. Moreover, answers do not necessarily represent true knowledge but are the result of guessing by using common sense, in order to preserve a positive self-image. As a result, a certain level of recall and information bias cannot be excluded and is difficult to measure and prevent.

\section{Conclusions}

Overall, a high percentage of participants were aware of the safety concerns associated with FQs. Knowledge was relatively good for the key safety concerns related to FQs among HPs. A notable impact on behavior was observed, mostly in terms of counselling of the patient and disseminating the information to fellow colleagues. Interestingly enough, despite the fact that all participants found drug-risk information to be of importance, a third admitted that keeping up to date was time-consuming. Participants who fully read the DHPC tended to generally score higher, implying a reasonably effective communication of key safety risks via the DHPC.

\section{Funding}

This study was supported by the "Iuliu Haţieganu" University of Medicine and Pharmacy, Cluj-Napoca (PCD 1529/32/18.01.19).

\section{References}

1. LiverTox: Clinical and Research Information on DrugInduced Liver Injury. Bethesda (MD): National Institute of Diabetes and Digestive and Kidney Diseases; 2012. Fluoroquinolones [Updated 2020 Mar 10]. Available from: https:/www.ncbi.nlm.nih.gov/books/NBK547840/

2. Oliphant CM, Green GM. Quinolones: a comprehensive review. Am Fam Physician. 2002;65:455-464.

3. European Medicines Agency: EMA/818158/2018. Pharmacovigilance RiskAssessmentCommittee(PRAC), 16 October 2018. Assessment report. Referral under Article 31 of Directive 2001/83/EC resulting from pharmacovigilance data. Available from: https://www.ema.europa.eu/en/ documents/referral/quinolone-fluoroquinolone-article-31referral-assessment-report_en.pdf
4. Stricker BH, Psaty BM. Detection, verification, and quantification of adverse drug reactions. BMJ. 2004;329:44-47.

5. Piening S, Haaijer-Ruskamp FM, de Graeff PA, Straus SM, Mol PG. Healthcare professionals' self-reported experiences and preferences related to direct healthcare professional communications: a survey conducted in the Netherlands. Drug Saf. 2012;35:1061-1072.

6. Goedecke T, Morales DR, Pacurariu A, Kurz X. Measuring the impact of medicines regulatory interventions Systematic review and methodological considerations. $\mathrm{Br}$ J Clin Pharmacol. 2018;84:419-433.

7. FDA (US Food and Drug Administration). FDA Drug Safety Communication: FDA updates warnings for oral and injectable fluoroquinolone antibiotics due to disabling side effects. Safety Announcement. Available from: https:// www.fda.gov/media/99425/download

8. de Vries ST, van der Sar MJM, Coleman AM, Escudero Y, Rodríguez Pascual A, Maciá Martínez MÁ, et al. Safety Communication Tools and Healthcare Professionals' Awareness of Specific Drug Safety Issues in Europe: A Survey Study. Drug Saf. 2018;41:713-724.

9. European Medicines Agency. Guideline on good pharmacovigilance practices (GVP) module XVI - risk minimisation measures: selection of tools and effectiveness indicators (rev 2) (EMA/204715/2012). 2017. Available from: http://www.ema.europa.eu/docs/en_GB/document library/Scientific_guideline/2014/02/WC500162051.pdf.

10. National Agency for Medicines and Medical Devices. Comunicare directă către profesioniștii din domeniul sănătății. Antibiotice sistemice și inhalatorii din clasa chinolonelor şi fluorochinolonelor - riscul de apariţie a reacțiilor adverse invalidante, de durată și potențial ireversibile și restricții privind utilizarea: Ciprofloxacină, levofloxacină, moxifloxacină, norfloxacină, ofloxacină, Pefloxacină [Direct communication to health professionals. Systemic and inhalation antibiotics in quinolones and fluoroquinolones class - risk of long-term disability and potentially irreversible adverse reactions and restrictions regarding use: Ciprofloxacin, levofloxacin, moxifloxacin, norfloxacin, ofloxacin, Pefloxacin, 2019]. Available from: https://www.anm.ro/_/COMUNICARI\%20DIRECTE/ Antibiotice\%20sistemice\%20și\%20inhalatorii\%20din\%20 clasa $\% 20$ chinolonelor\%20și\%20fluorochinolonelor_ DHPC.pdf

11. Lem J, Younus M, Aram JA, Moosavi S, Freivogel $\mathrm{K}$, Lewis A, et al. Evaluation of the Effectiveness of Additional Risk Minimization Measures for Voriconazole in the EU: Findings and Lessons Learned from a Healthcare Professional Survey. Pharmaceut Med. 2019;33:121-133.

12. Vora P, Artime E, Soriano-Gabarró M, Qizilbash N, Singh V, Asiimwe A. A review of studies evaluating the effectiveness of risk minimisation measures in Europe using the European Union electronic Register of PostAuthorization Studies. Pharmacoepidemiol Drug Saf. 2018;27:695-706.

13. Landsberg W, Al-Dakkak I, Coppin-Renz A, Geis U, PetersStrickland T, van Heumen E, et al. Effectiveness Evaluation of Additional Risk Minimization Measures for Adolescent 
Use of Aripiprazole in the European Union: Results from a Post-Authorization Safety Study. Drug Saf. 2018;41:797-806.

14. Artime E, Qizilbash N, Garrido-Estepa M, Vora P, SorianoGabarró M, Asiimwe A, et al. Are risk minimization measures for approved drugs in Europe effective? A systematic review. Expert Opin Drug Saf. 2019;18:443454.

15. Théophile H, Miremont-Salamé G, Robinson P, Moore N, Bégaud B, Haramburu F. Relevance of a "Dear Doctor letter" to alert healthcare providers to new recommendations for vitamin D administration. Eur J Clin Pharmacol. 2011;67:681-686.

16. Bester N, Di Vito-Smith M, McGarry T, Riffkin M, Kaehler S, Pilot R, et al. The Effectiveness of an Educational Brochure as a Risk Minimization Activity to
Communicate Important Rare Adverse Events to HealthCare Professionals. Adv Ther. 2016;33:167-177.

17. Brown P, Bahri P. 'Engagement' of patients and healthcare professionals in regulatory pharmacovigilance: establishing a conceptual and methodological framework. Eur J Clin Pharmacol. 2019;75:1181-1192.

18. Petraceck J. (16-17 September 2020) Clever medication process design with built-in risks management. IsoP patient safety Day 2020. Available from: https://www.youtube. $\mathrm{com} /$ watch? $\mathrm{v}=$ EmsQmKXdikI

19. Mol PG, Straus SM, Piening S, de Vries JT, de Graeff PA, Haaijer-Ruskamp FM. A decade of safety-related regulatory action in the Netherlands: a retrospective analysis of direct healthcare professional communications from 1999 to 2009. Drug Saf. 2010;33:463-474. 